Review

\title{
Labour inspections and the prevention of psychosocial risks at work: A realist synthesis
}

\author{
Rafaël Weissbrodt ${ }^{\mathrm{a}, *}$, David Giauque ${ }^{\mathrm{b}}$ \\ ${ }^{a}$ State Secretariat for Economic Affairs (SECO), Labour Directorate, Working Conditions, Labour and Health, Holzikofenweg 36, CH-3003 Bern, Switzerland

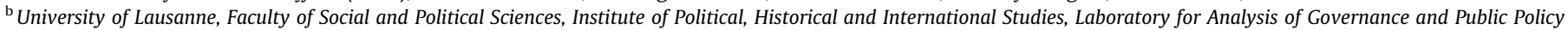 \\ in Europe, Quartier UNIL-Mouline, Bâtiment Géopolis, CH-1015 Lausanne, Switzerland
}

\section{A R T I C L E I N F O}

\section{Article history:}

Received 7 July 2016

Received in revised form 21 December 2016

Accepted 17 February 2017

Available online 1 April 2017

\section{Keywords:}

Labour inspection

Psychosocial risks

Psychosocial work environment

Realist synthesis

Literature review

Systematic review

\begin{abstract}
A B S T R A C T
Background: Little research exists on the effectiveness of workplace visits by labour inspectors in relation to psychosocial risks. The study aimed to produce a consistent and transferable evidence-based framework.

Methods: We conducted a systematic literature review using the realist synthesis approach. Searches in three electronic databases, systematic hand-searches in five specialised journals and iterative purposive searches yielded 25 publications. The initial search included any study between 2000 and 2015 containing information on labour inspectorates and psychosocial risks or stress at work. We conducted a complementary search to identify publications from French-speaking authors.

Results: The synthesis yielded a conceptual model relating public intervention measures, mechanisms of action, outcomes and contexts. Publications indicate positive outcomes in 4 cases, possibly positive in 2 , mixed outcomes in 4 , and no or poor effects in 10 . Studies from Nordic countries show some positive outcomes of inspection activities based on dialogue with employers, group interviews with employees, repeated visits and combinations with other communication and information channels, in the context of highly organised labour markets. Conversely, other studies highlight the limitations of intervention strategies that rely on an "enlightenment" principle, in a context of increasingly precarious and flexible work situations.

Conclusion: The synthesis suggests the possibility of positive outcomes of inspectors' interventions on psychosocial risks in supportive contexts and with appropriate training and resources. However, strong evidence is lacking and more evaluation studies are necessary. A comprehensive conceptual framework may help to analyse the wide range of factors influencing the effectiveness of workplace visits by inspectors.
\end{abstract}

(c) 2017 Elsevier Ltd. All rights reserved.

\section{Contents}

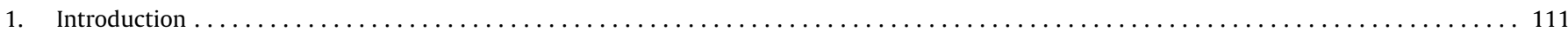

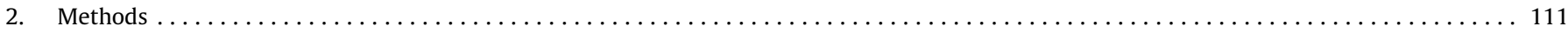

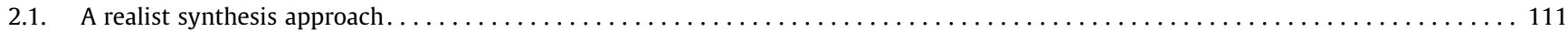

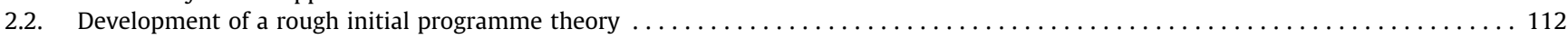

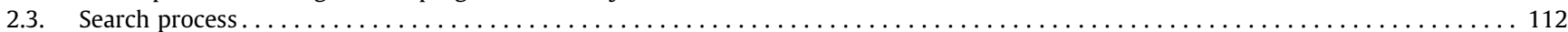

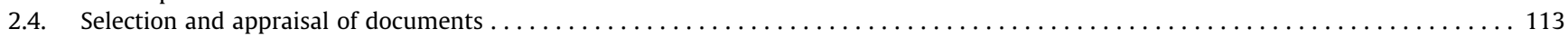

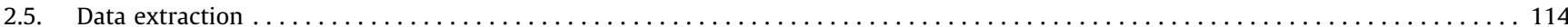

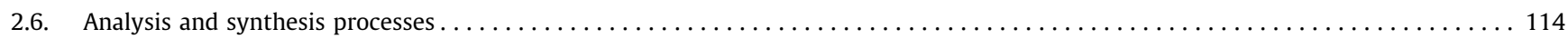

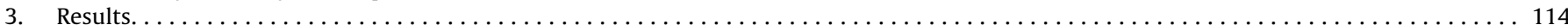

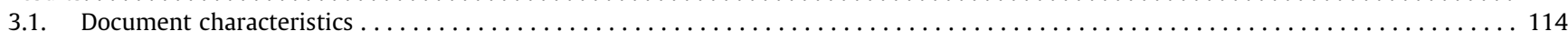

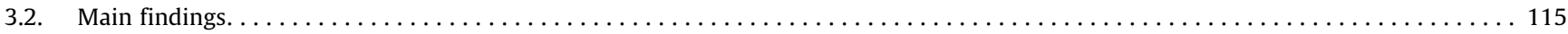

\footnotetext{
* Corresponding author.

E-mail addresses: grweissbrodt@bluewin.ch (R. Weissbrodt), david.giauque@unil.ch (D. Giauque).
} 


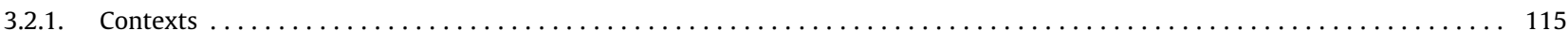

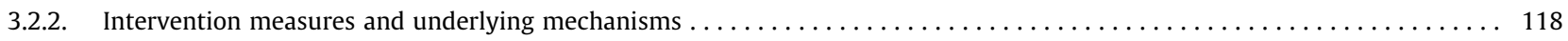

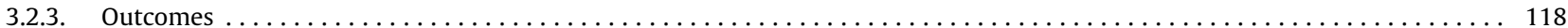

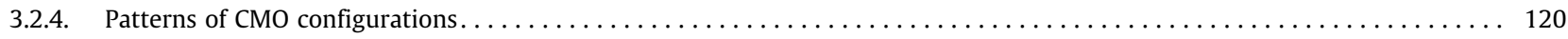

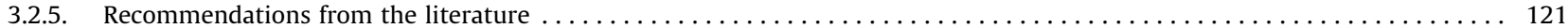

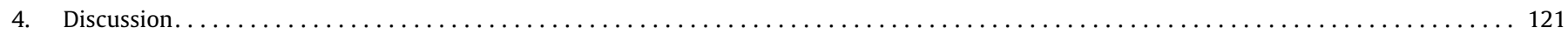

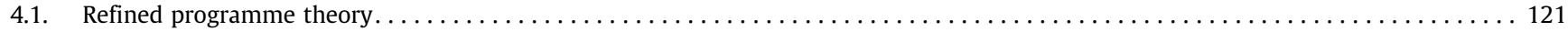

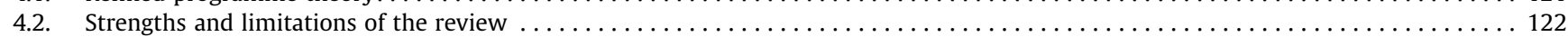

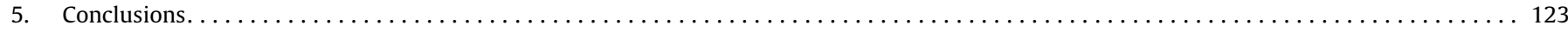

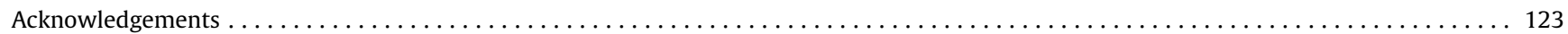

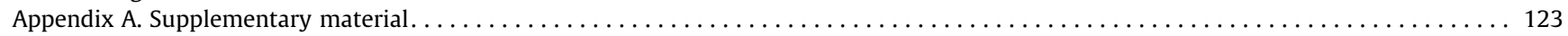

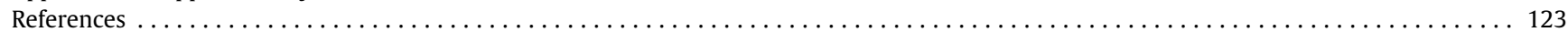

\section{Introduction}

In the last decades, most industrialised countries have endorsed regulations requiring systematic occupational health and safety management. General duty provisions stipulate that employers have to assess and prevent all occupational health risks. The integration of organisational and psychosocial health risks into the scope of occupational health and safety (OHS) has challenged the roles and daily practices of labour inspectors, who were traditionally more comfortable with technical issues. The present paper concentrates on the inclusion of psychosocial risks and the assessment of the psychosocial work environment in the strategies and actions of labour inspectorates. It aims at providing a systematic review of the publications dealing with this topic.

According to Leka and Cox (2008), "work-related psychosocial risks concern aspects of the design and management of work and its social and organisational contexts that have the potential for causing psychological or physical harm". This multifaceted notion combines health outcomes (fatigue, mental disorders, mental attrition, burnout, cardiovascular diseases, and other forms of suffering), pathogenic processes (stress reactions), and risk factors related to the work organisation and interpersonal relationships (e.g. overload, threats, violence, harassment, restricted autonomy, lack of recognition, etc.).

For the last 15 years, there has been an increasing number of publications on national and international psychosocial risk policies. They often present descriptive accounts, perspectives on the challenges for regulators and suggestions for the future. Most of them address the situation in Europe, considered the "cradle of Occupational Health" (Gagliardi et al., 2012). For example, Leka et al. (2015a) conducted a review of 94 hard and soft law policies on psychosocial risks and mental health in Europe. Ertel et al. (2010) examined the role of European social dialogue in the field of psychosocial risks; they identified diverging perspectives and structural weaknesses. In France, de Gaulejac (2010) undertook a review of three governmental reports; he criticised the refusal to tackle structural causes, such as work organisation, management ideology and the “liberalist dogma” (p. 65). Several authors (Langenhan et al., 2013; Leka et al., 2011b; Zoni and Lucchini, 2012) found a gap between policy and practice. Workplaces do not sufficiently understand and incorporate psychosocial risks into strategic decision-making, and do not know how to manage them adequately. The European Framework for Psychosocial Risk Management (PRIMA-EF) was developed to tackle these challenges (Leka et al., 2011a). It provides a model and indicators for the management of psychosocial issues by governments and companies. Finally, some studies emphasize that developing countries are not free from psychosocial risks (Cheng, 2015; Kortum and Leka, 2014; Kortum et al., 2010).

A few other studies focus on an operational level, exploring how labour inspectors consider psychosocial risks in their daily practices. A systematic review of this type of publication could be useful for government agencies confronted with the difficulty of tackling these issues. Previous systematic reviews have measured the impact of labour inspections in terms of injuries and occupational diseases (MacEachen et al., 2016; Mischke et al., 2013), but to our knowledge, there has not been any systematic review on labour inspector intervention for the prevention of psychosocial risks. Many countries have launched intervention programmes over the past 20 years. However, an overview of their contents, results, success factors, and limitations is lacking. The development of an evidence-based programme theory could help labour inspectorates identify what kinds of interventions could be fruitful, in which contexts, and by which mechanisms. For this purpose, we sought to answer two questions. First, which inspection practices have been developed in industrialised countries? Secondly, what have been their impact, in which contexts and by which mechanisms? We studied these questions through a realist synthesis approach.

\section{Methods}

\subsection{A realist synthesis approach}

The aim of a systematic literature review is to synthesise the available, high quality evidence on the effects of an intervention. This is interesting for policy-makers, because it delivers an overview of the outcomes of policy instruments, based on a transparent and rigorous process (Victor, 2008a,b). For instance, Robson et al. (2007) studied the effectiveness of OHS management systems, and Tompa et al. (2007) the prevention incentives of insurance and regulatory mechanisms. To date, more than 130 systematic reviews on health and safety topics are available in the Cochrane Library (osh.cochrane.org). Specifically, Mischke et al. (2013) conducted a systematic review on enforcement tools for preventing occupational diseases and injuries. They found evidence that inspections decrease injuries in the long term but not in the short term. The magnitude of the effect and the impact of fines and penalties are uncertain. Larger effects are attained by specific rather than general inspections.

The Cochrane criteria are usually considered the gold standard for reviews in safety research, with randomised controlled trials (RCTs) and quasi-experimental alternatives being the preferred methods (Pedersen et al., 2012; Verbeek and Ruotsalainen, 2012). According to Berthelette et al. (2008), systematic reviews often exclude other types of designs, deemed as methodologically weak, when results from RCTs are available; however, these authors recommend complementing this approach by evaluative research and qualitative methods, to identify the reasons why an intervention does - or not - lead to the expected outcomes.

Our initial exploratory work revealed that very few studies collected quantitative data on our review topic. Most publications describe state intervention measures, their contexts and sometimes their outcomes or mechanisms of action. It also turned out 


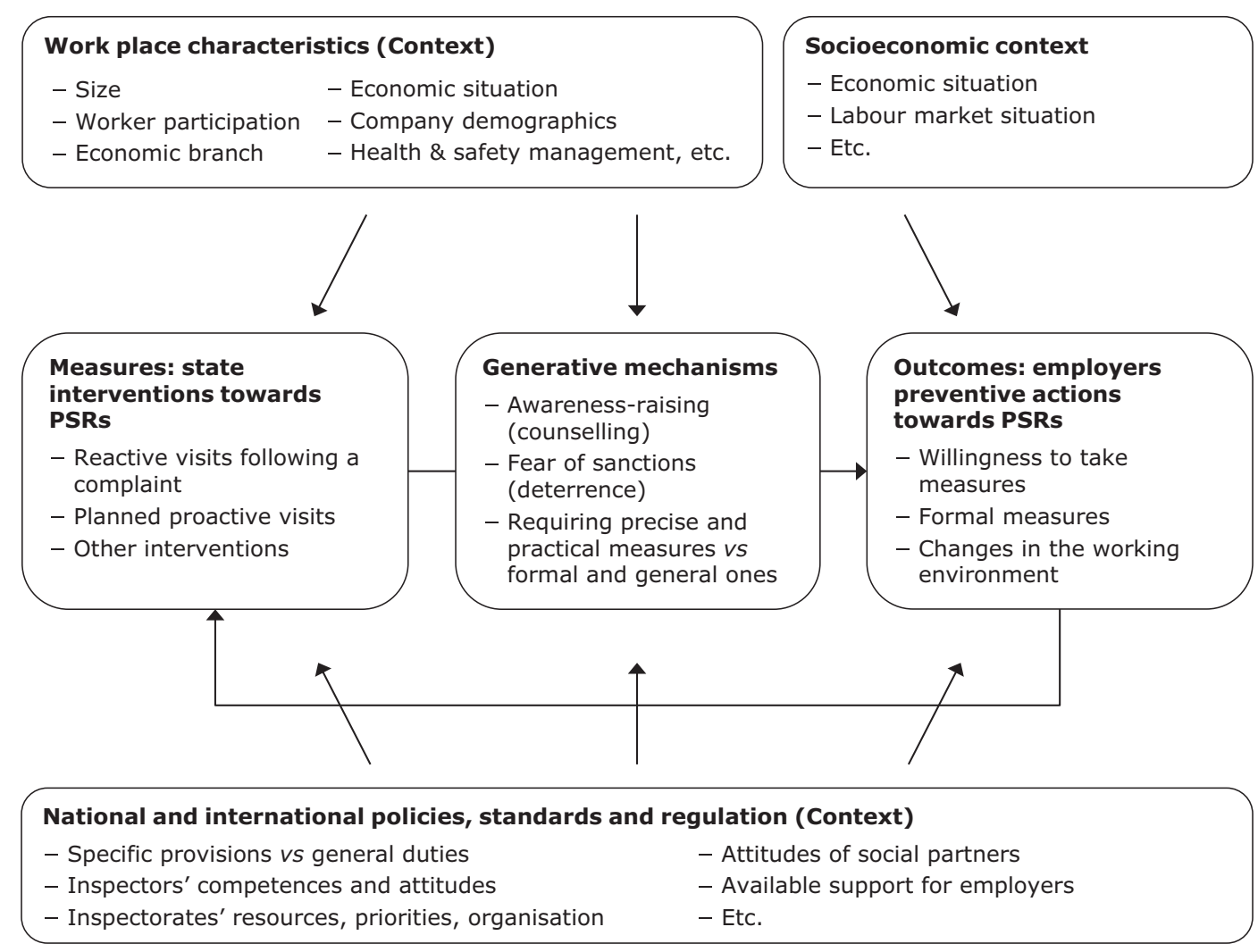

Fig. 1. Initial rough programme theory.

that a sound understanding of the socio-political context of a given country is necessary to evaluate the outcomes of policy interventions toward psychosocial risks (Cheng, 2015). For these reasons, a realist synthesis seemed an appropriate method. Realist synthesis (or realist review) is well suited for the review of complex interventions (Pawson, 2002; Rycroft-Malone et al., 2012). It tries to answer the question "What works for whom under what circumstances, how and why" (Wong et al., 2013a); it unveils interactions between contexts, mechanisms and outcomes (CMO configurations). Beyond assessing effectiveness, realist synthesis aims at developing theories. Wong et al. (2013b) recommend constructing a rough initial programme theory before beginning the review. It should sketch what is supposed to happen and why it is supposed to work. In the course of the review, evidence is gathered to assess its relevance and contribute to its evolution. The output is an enriched programme theory describing the ways different contexts trigger different mechanisms and generate different outcomes. The search for and appraisal of evidence are guided by primary research's contribution to this development process; multiple types of evidence may be included (Rycroft-Malone et al., 2012). Recent literature offers various examples of realist syntheses approaches to public health topics (Wong et al., 2011), management of sickness absence (Higgins et al., 2012) or health and safety committees (Yassi et al., 2013).

\subsection{Development of a rough initial programme theory}

In order to sketch a theoretical model, we began with an exploratory literature search with Google Scholar and in Thomson Reuters' Web of Science. We contacted researchers abroad and talked with Swiss government representatives. A special issue of Safety Science (Lippel and Quinlan, 2011) also delivered a first overview of the field. A model by Baril-Gingras et al. (2006) inspired further developments; it aims to explain the processes leading to preventive changes inside workplaces during OHS interventions conducted by external advisors.

Fig. 1 depicts our initial rough theory of labour inspectors' interventions on psychosocial risks. It starts with the regulatory measures implemented by authorities, mainly reactive and proactive workplace inspections (Walters et al., 2011). These measures aim at raising employers' willingness to prevent psychosocial risk, and lead them to implement preventive actions (outcomes). These may be either formal (e.g. workplace policies) or practical. Several mechanisms may result in such shifts of attitudes. Counselling may raise awareness; controlling may have a deterring effect; and requiring specific types of measures (e.g. formal and general $v s$ specific and practical) may influence an employer's reasoning and reactions. Positive effects occur if a supportive context triggers the generative mechanisms; Lippel and Quinlan (2011) list a series of factors pertaining to the regulatory background. The socioeconomic context certainly has an influence, too. Finally, workplace characteristics (size, branch, etc.) may influence the management of psychosocial risks (Jain, 2011) and an employer's reactions to an inspection.

We presented this initial theory to stakeholders within the Federal Secretariat for Economic Affairs (SECO), the Swiss government agency that supervises the activities of the cantonal labour inspectorates. We also informally discussed it with labour inspectors and other specialists active in the field. The model served as a backbone for the whole review process (search strategy, search terms, inclusion and exclusion criteria, data extraction form, data coding, analysis and synthesis).

\subsection{Search process}

The main search took place in the Web of Science Core Collection (English, French, German, Italian, Spanish), MEDLINE (all lan- 


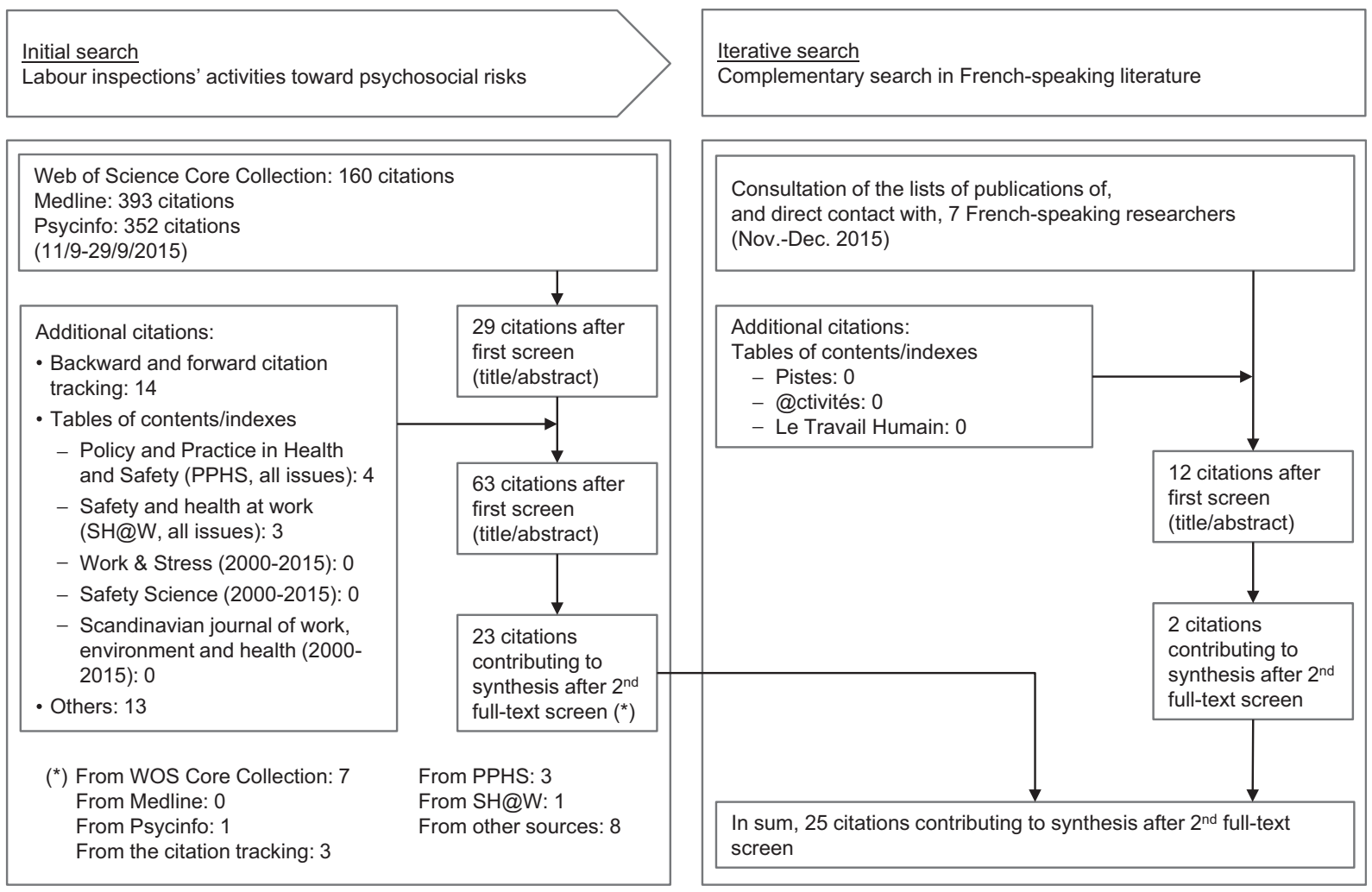

Fig. 2. Flow diagram of the search process.

Table 1

Inclusion and exclusion criteria.

\author{
Inclusion criteria \\ The publication addresses interventions of labour inspectorates in connection with psychosocial risks or stress at work \\ More general papers on psychosocial risk policies are included only if labour inspection is explicitly addressed \\ Exclusion criteria \\ Publications dealing mainly or strictly with: \\ - Impacts of occupational risks on health \\ - Causes of and risk factors for psychosocial risks \\ - A specific psychosocial risk (e.g. aggression, bullying, harassment, burnout, ethnic or gender discrimination, etc.) \\ - Epidemiology of psychosocial risks \\ - Preventive interventions inside workplaces, unrelated to public authorities \\ - Therapeutic treatments for occupational health problems \\ - Psychometric measures of psychosocial risks \\ - Court cases or interpretations of legal provisions, unrelated to broader public policies or inspector intervention \\ - Description of a national regime for occupational risk prevention \\ - Countries other than developed countries with market economy
}

guages), and Psycinfo (all languages), for the years 2000-2015. We developed a list of search terms for each database (see Additional file 1 , available for download on the journal's website). MeSH terms were used in MEDLINE when available. We complemented the search process by citation-tracking and consultation of tables of contents or indexes of specialised journals (see Fig. 2 in Section 3.1 for details). We also included papers retrieved from the initial exploratory search.

An additional search aimed at identifying publications by French-speaking authors, some of which are critical regarding the concept of psychosocial risks (Bouffartigue, 2012; Davezies, 2001; Lhuilier, 2010; Loriol, 2010). They consider that it too often leads to individual-oriented preventive measures rather than collective debates inside the workplaces. Protecting health at work should be primarily about creating conditions in which individuals and groups can develop the quality of their work and their competencies. Authors referring to such a developmental approach might have a specific way of considering labour inspection of psychosocial risks. As only very few publications by French-speaking researchers were found in the databases in the first step, we searched for references in the lists of publications of seven authors from Belgium, France and Québec. We also directly asked them for relevant publications. Finally, we read the tables of contents of several French-written scientific journals (see Fig. 2).

\subsection{Selection and appraisal of documents}

Table 1 lists the inclusion and exclusion criteria; they were chosen by the two authors, in cooperation with other researchers within the SECO.

Realist reviews do not necessarily rely on quality evaluation checklists. The selection and appraisal process deals above all with a publication's contribution to the development of the programme theory (Gillespie and Marshall, 2015). Wong et al. (2013a) recom- 
Table 2

Impact ladder (Hansen et al., 2015).

\begin{tabular}{ll}
\hline Impact of working environment inspections \\
\hline Step 7 & Improved health, including reduction of absenteeism due to sickness \\
Step 6 & Reduction in the rate of industrial accidents and work-related diseases \\
Step 5 & Reduction in exposures, including risks of accidents \\
Step 4 & Improved (safer) production technology and safer work processes \\
Step 3 & Improvements in the enterprises' working environment efforts \\
Step 2 & Changes in attitudes at the workplaces \\
Step 1 & Changes in knowledge at the workplaces \\
\hline
\end{tabular}

mend evaluating the rigor of any section of data within a document, i.e. whether the methods used to generate the data are credible and trustworthy. However, they specify that useful data exist even in methodologically weak studies and other sources. We used three categories for a simple appraisal of rigor: high for peerreviewed publications relying on empirical data, medium for peerreviewed documents not based on empirical data (or conversely), and low for non-peer-reviewed documents not based on empirical data. This notion of rigor applies only to the way a publication dealt with psychosocial inspection; it is not a judgement on the rigor of the whole publication. This is important to point out, as several publications address this issue only as a secondary topic.

Due to limited resources, only the first author conducted the search, selection and appraisal of publications. However, the authors planned every step together and regularly discussed the review process.

\subsection{Data extraction}

We devised a data extraction form consisting of two main parts. The first dealt with a publication's general characteristics: authors, year, type, objectives, studied countries, focus and methods. The second part served to extract information in realistic terms: intervention measures, contexts, mechanisms and outcomes. As no publication adopted a realist perspective, data extraction involved interpretation, in order to assign the elements of information to one or the other section of the form. It is indeed often difficult to distinguish between contexts and mechanisms (Dalkin et al., 2015) or between mechanisms and interventions (Marchal et al., 2012). To address these challenges, we adopted the definition proposed by Wong et al. (2013b): mechanisms are invisible, causal processes that explain how the infrastructure and the resources of a programme lead to specific decisions or behaviours among stakeholders in specific contexts. It may be factors such as reasoning, preferences, norms or collective beliefs. To infer them from the data, these authors recommend mentally reconstructing a stakeholder's reasoning.

The first author carried out the data extraction for every publication. He summarised all forms in two tables corresponding to the two parts of the form. The second author checked their content for consistency, however without systematically rereading the articles. This check did not lead to significant changes of the coding. Both tables can be downloaded as Supplementary Material (Additional files 2 and 3 ).

\subsection{Analysis and synthesis processes}

We extracted at least one context-mechanism-outcome configuration out of every publication. Configurations were deemed complete when they provided at least some information on contexts, mechanisms and outcomes, and partial when one or more category was missing. The next step was to hand code the material through a classical iterative process, with themes gradually emerging from the dataset (Creswell, 2014). Whenever mentioned, inter- vention outcomes were qualified as poor, mixed, possibly positive or positive. We further coded them depending on their type, using an impact ladder described in Table 2 (Hansen et al., 2015). This process allowed for a "quantitizing" (Tashakkori and Teddlie, 1998) of mostly qualitative data, in order to compute frequencies and cross-tabulations. To compensate for the drawbacks of having only one researcher coding the data, we systematically kept track of the process (see Additional file 4 for the coding scheme, and Additional files 2 and 3 for the coded data).

Finally, we synthesised the results by filling in the boxes of the initial rough theoretical model with the themes that emerged from the analysis. We identified two particularly illustrative and synthetic CMO configurations - one negative and one positive - and used them to exemplify how contexts shape the intervention methods of labour inspectors, as well as their impact.

\section{Results}

\subsection{Document characteristics}

Fig. 2 depicts the searching process. One fourth of the papers (6/25) were published between 2004 and 2009, and 19 after 2010. About two thirds (17/25) came from peer-reviewed journals. Only 3 were primary research papers using quantitative data (Rasmussen et al., 2011; SLIC, 2012; Stadler and Splittgerber, 2014). Every other study employed qualitative methods (17) or narrative reviews (5). However, some of them reported on quantitative results from grey literature (Hansen et al., 2015; Johnstone et al., 2011; Velásquez, 2012). Half of the papers (13) fulfilled our criteria for high rigor, 8 for medium and 4 for low rigor. Overall, we extracted $30 \mathrm{CMO}$ configurations; 21 were complete and 9 partial, of which 7 did not include information on outcomes and 2 on mechanisms.

Almost half of the publications (11) originated in Nordic countries, and 8 in other European countries. Some papers came from Australia (3) and Canada (1), and 2 covered several countries or continents. The majority (16) focussed on our specific review topic - inspection of the psychosocial work environment. The others indirectly addressed this issue through standards, policies and regulations on psychosocial risks (5), inspection of occupational health and safety (3), and participation and social dialogue (1). Papers aimed at describing, evaluating or developing methods and instruments for psychosocial risk inspections (15), analysing inspection practices and processes (9), barriers and resources for regulatory interventions (8), legal provisions (5), stakeholders' attitudes (5), and impacts of macro-level political, organisational or socioeconomic changes on inspection activity (3).

Only 5 papers specifically aimed at evaluating outcomes of interventions. Frick (2014) conducted a review of 270 case studies of labour inspectorates' interventions in Sweden. Hansen et al. (2015) reported on the results of two inquiries: one was a telephone survey of companies visited by the Danish Work Environment Authority; the other was a comparison of two groups of randomly selected enterprises in Norway, one of which had 
undergone an inspection visit. Quinlan et al. (2009) evaluated outcomes through document analysis, interviews with regulatory managers and inspectors, and observations at workplace visits. The report by the Committee of Senior Labour Inspectors on its European inspection campaign on psychosocial risks (SLIC, 2012) was based on 23 country reports with quantitative and qualitative questions. Finally, Starheim (2014) measured outcomes through case studies of workplaces visited by Danish inspectors. She relied on semi-structured group and individual interviews with workplace representatives and workshops at some workplaces.

\subsection{Main findings}

The presentation of the results follows the structure of the initial rough programme theory. We proceed from macro to micro levels, beginning with the contextual dimensions, continuing with the intervention measures and their underlying mechanisms and finishing with the outcomes. Fig. 3 visually synthesises the data, showing all the categories and subcategories derived from the coding process.

\subsubsection{Contexts}

We extracted 216 elements of information on the contexts. We coded them in 3 overarching classes and 15 categories. The amount of data regarding contexts was much larger than for the other dimensions of the initial rough programme theory. To account for this variety, we further defined 36 subcategories. The largest class of information concerned policies, standards and regulation (148 elements of information), followed by the socioeconomic context (38 elements) and finally by workplace characteristics (30 elements).

3.2.1.1. Policies, standards and regulation. The most frequent category was legislation. Several publications in Noridc countries reported on the existence of provisions on the psychosocial work environment and on bullying (Hansen et al., 2015; Saksvik et al., 2007). Others reported on legislation pertaining to specific risk factors in several EU countries (SLIC, 2012). However, according to nearly one third of the publications, there is a lack of specific or clear legal provisions. On the other hand, several authors noted that general legal duties encompass the psychosocial risks (Bruhn and Frick, 2011; Frick, 2014; Hansen et al., 2015; Johnstone et al., 2011; Toukas et al., 2015). For this reason, Lerouge (2014) and Velásquez (2012) consider that there is no normative void for psychosocial risks in Europe. According to Velásquez, the existence of a specific legislation does not have a determining influence on workplace practices. Nevertheless, Lippel and Quinlan (2011) argue that the lack of specific provisions increases the threat of litigation by employers against inspectors' requirements. In the Canadian state of Québec, Lippel et al. (2011) noted that several important OHS provisions apply only to minority sectors, excluding industries with high psychosocial burdens. Finally, Lippel and Quinlan (2011) and Lippel et al. (2011) described rising compensation costs as an incentive to regulate on psychosocial risks; however, they drew attention to the relative invisibility of these risks to compensation insurers.

The next most frequent category concerned the scope of interventions by authorities. Several authors described how the complexity of working life challenges labour inspectors and leads to an expansion of the work environment concept (Bruhn, 2006, 2009; Bruhn and Frick, 2011; Starheim and Bøgehus, 2014). There is a typical evolution in many countries, from an initial focus on harassment and violence toward a broader understanding of psychosocial risks (Lippel and Quinlan, 2011). Walters et al. (2011), Bruhn and Frick (2011) and Frick (2014) reported on the regulatory shift toward "regulated self-regulation" (or "process regulation"), that is the duty to have some form of internal regulation within companies. Hansen et al. (2015) explained that Nordic countries have developed a risk factor approach to psychosocial inspections. They have practices on factors such as violence, bullying and sexual harassment, while work hours and some other risk factors are not part of inspection duties in several countries. For example, in Denmark, inspectors may not intervene on psychosocial problems resulting from decisions by management that can be solved in collaboration with employees, such as compensation issues, lack of meaningful work, and job insecurity (Rasmussen et al., 2011). The broadening scope of intervention raises interpretation issues; the notion of psychosocial risks lacks clarity (Leka et al., 2015b), and there is a slightly different understanding even between the Nordic countries (Hansen et al., 2015). According to Bruhn and Frick (2011), WEA managers in Sweden underestimated the complexity of these issues and this contributed to the difficulty of developing new inspection methods.

Nearly half of the publications addressed inspection strategies on psychosocial risks. Some authors described varying inspection methods, purposes and initiatives across countries. Nordic countries have a broad understanding of the psychosocial work environment, and Southern European countries a more restrictive occupational hazards approach (Lerouge, 2014). The psychosocial work environment is a priority area in Northern Europe; Denmark and Finland have quantitative goals for stress reduction (Hansen et al., 2015). Some Nordic inspectorates conduct specific psychosocial assessments, while others focus on the systematic work environment efforts by the enterprises. In any case, only Danish inspectors routinely carry out psychosocial risk assessments in most workplaces. Inspectorates internationally are becoming more active in this area (Lippel and Quinlan, 2011). However, Walters et al. (2011) contended that, overall, agencies do not have clear inspection strategies to achieve improved management of $\mathrm{OSH}$, nor adequate resources to deal with the consequences of the changing world of work and the change of balance between capital and labour. According to Quinlan (2007), Australian authorities have neglected the issue of downsizing/restructuring, seen as a managerial prerogative. Finally, two publications addressed strategic dilemmas faced by inspectorates: Bruhn (2006) reported on the difficult choice between their controlling and counselling roles, and Starheim and Bøgehus (2014) on the contradictions between the WEA's strategy of reducing the duration of inspections and the inspectors' views about the necessary success conditions.

Several publications showed very contrasting practices across countries, depending on whether the authorities focus on substance, process, individual cases, work organisation and design, litigation, compensation or prevention (Lerouge, 2014; Lippel and Quinlan, 2011). Mellor et al. (2011) specifically studied the implementation of the British Management Standards, which are the main public policy approach developed in the UK for preventing stress at work. They highlighted the potential and the barriers for an effective implementation of the Standards, as assessed by labour inspectors. Other publications reported on tools and methods developed to address psychosocial issues. Hansen et al. (2015) described methods used in Nordic countries, mainly meetings with management, interviews with employees, inspection guidelines, and surveys completed by employees during inspection visits. In Australia, Johnstone et al. (2011) indicated that codes of practice and guidance material have been developed for limited groups of risk factors. According to the SLIC (2012), inspection methods need to be adapted to each national context.

Some authors reported on shortcomings of public policy interventions. Improvement notices on psychosocial issues remain rare, even in Nordic countries (Hansen et al., 2015). In Australia, psychosocial risks are a marginal issue in visits, despite the significant level of concern among inspectors. Moreover, the exploration of 


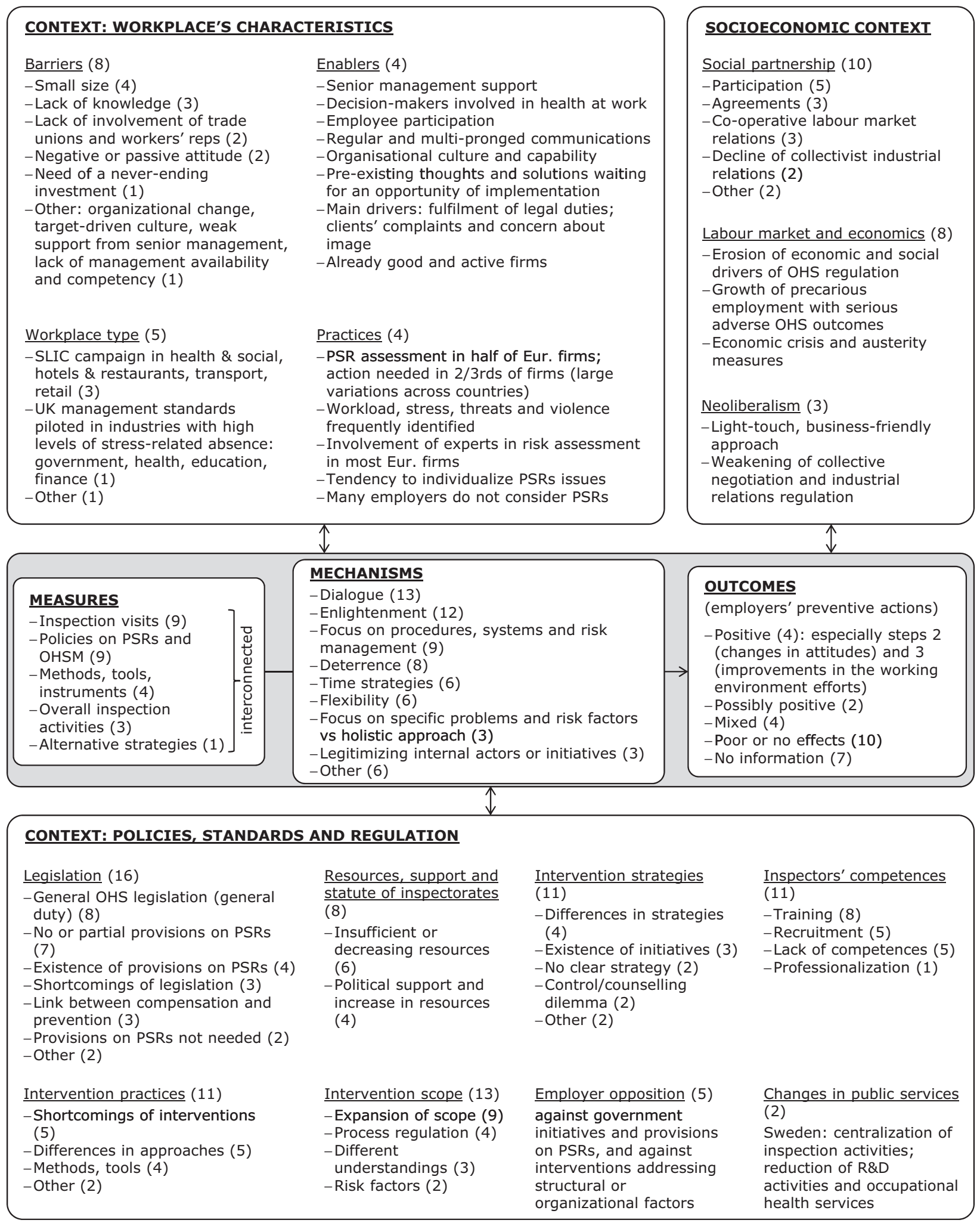

Fig. 3. Overall synthesis of the measures, contexts, mechanisms and outcomes identified in the 25 references. Between brackets: number of publications citing an element. PSRs $=$ psychosocial risks.

harassment and bullying claims entail difficulties: a problematic reliance on verbal evidence, time-consuming investigations, mostly formal preventive measures advocated by agencies and a limited impact (Johnstone et al., 2011; Quinlan, 2007). Walters et al. (2011) asserted that there has not been any sustained change in inspection practice after the introduction of "process regulation". There is an increased focus on procedural issues rather than a fundamental change.

Inspectors' competences on psychosocial issues were also frequently addressed. Inspectors have long been recruited for their 
technical qualifications. They are therefore often unfamiliar with psychological risk factors (Lerouge, 2012; Stadler and Splittgerber, 2014; Toukas et al., 2015). In Europe, some countries had never inspected psychosocial risks before the SLIC campaign (SLIC, 2012). Accordingly, training, mentoring and guidance are necessary (Bruhn, 2006; Hansen et al., 2015; Johnstone et al., 2011; SLIC, 2012; Stadler and Splittgerber, 2014). Lippel and Quinlan (2011) described a gradual learning process. Several authors also reported on changes in the recruitment of inspectors. Inspectorates begin to hire inspectors with an academic background and competences in behavioural and group issues (Bruhn and Frick, 2011; Johnstone et al., 2011; Lippel et al., 2011). According to Bruhn (2009), the strategy for professionalization of inspectors in Sweden remains weak. Changes in recruitment led to a cultural gap between traditional and mostly male inspectors with a technical background and newly hired, mostly female, human sciences specialists.

Some publications provided additional information on the resources, support and statutes of labour inspectorates. Publications from Denmark and Sweden reported on the political support and an increase of resources for inspectorates, at least for some time (Bruhn, 2009; Bruhn and Frick, 2011; Rasmussen et al., 2011). On the other hand, publications from several countries either reported on insufficient resources for inspectorates to perform their tasks in a context of growing complexity, or even on a decrease of their resources and a weakening of their influence (Frick, 2014; Leka et al., 2015b; Lerouge, 2012; Lippel and Quinlan, 2011; Walters et al., 2011).

Finally, a few publications reported on employers' opposition to government initiatives and legislative provisions on psychosocial risks and to interventions addressing structural and organisational factors (Frick, 2014; Johnstone et al., 2011; Leka et al., 2015b; Lippel and Quinlan, 2011; Quinlan, 2007).

3.2.1.2. Socioeconomic context. The social partnership was addressed in almost half of the publications. According to the SLIC (2012), employees or representatives are involved in the risk assessment in most companies and countries. On the other hand, Stadler and Splittgerber (2014) reported on a lack of information gathered from employees during the SLIC campaign in Germany, because of the rarity of workers' representatives in industries with a high percentage of small companies. Walters et al. (2011) stated that the introduction of "process regulation" in most countries was not accompanied by overt strategies to increase worker participation.

Nordic authors, in a context of highly organised labour markets, described the role of agreements between social partners in the regulation of the work environment. Hasle and Petersen (2004) mentioned an increasing difficulty in distinguishing between regulation and agreements in Denmark. They raised questions about the balance between these two different conceptions of state intervention: agreements are characterised by a weak system of implementation and may limit the scope of intervention of inspectors, e.g. on working hours (Hansen et al., 2015; Rasmussen et al., 2011). The three publications from Australia (Johnstone et al., 2011; Quinlan, 2007; Quinlan et al., 2009) showed a different context, marked by a decrease in union density and a retreat of industrial relations regulation. Finally, Hasle and Petersen (2004) highlighted the increasing proximity between the two fields of OHS regulation and industrial relations. Psychosocial factors are related to industrial relations issues such as flexible work, working hours, outsourcing, temporary employment and intensity of work. Moreover, the trend toward deregulation makes it difficult to argue for stricter legislation; collective agreements might be an alternative approach.
Several publications reported on changes in the labour market leading to an erosion of economic and social drivers of OHS regulation. Precarious employment and flexible work arrangements are increasing (small firms, self-employed, temporary workers, downsizing, mergers and acquisitions, unsuccessful change processes, etc.). These changes weaken OHS regimes, increase psychosocial risks, and make it difficult for inspectors to reach workplaces. Economic crisis and austerity measures contribute to this trend. The neoliberal climate promotes a light-touch, business-friendly approach, but also undermines collective negotiation and industrial relations regulation (Frick, 2014; Leka et al., 2015b; Quinlan, 2007; Saksvik et al., 2007; Stadler and Splittgerber, 2014; Toukas et al., 2015; Walters et al., 2011).

3.2.1.3. Workplace characteristics. Overall, there is little information on workplace practices for managing the psychosocial work environment. According to the SLIC report (2012), more than half of the workplaces have made a psychosocial risk assessment (with large variations across countries). Workload, stress, threats and violence were frequently identified, and action was needed in two thirds of the workplaces (again with large variations); experts were involved in the risk assessment in most companies. Stadler and Splittgerber (2014) reported that an appropriate risk assessment had been conducted in half of the workplaces visited during the SLIC campaign in Germany; management of stress factors seemed to have been integrated in $15-25 \%$ of workplaces, and measures against psychosocial risks implemented in $20 \%$ of the companies. Frick (2014) observed a tendency for companies to individualise work environment issues, and Toukas et al. (2015) contended that many employers do not consider psychosocial risks. A third of the publications identified barriers to psychosocial risk management within workplaces. The most common are the small size of workplaces (Bruhn and Frick, 2011; Hasle and Petersen, 2004; Leka et al., 2015b; SLIC, 2012) and their lack of knowledge (Jespersen et al., 2014; Mellor et al., 2011; SLIC, 2012). Other barriers are a lack of involvement of trade unions and workers representatives, a negative or passive attitude of companies and the necessity of a considerable and never-ending investment from employers for systematic OHS management (Hasle and Petersen, 2004; Mellor et al., 2011; Walters et al., 2011). Mellor et al. (2011) mentioned yet other barriers, such as organisational change, a target-driven culture, weak support from senior management and a lack of management availability and competency.

A few publications pointed at enablers within workplaces: senior management support, involvement of decision-makers, employee participation, regular and multi-pronged communications, organisational culture and capability, pre-existing thoughts and solutions waiting for an opportunity for implementation (Mellor et al., 2011; Starheim, 2014). According to the European Survey on New and Emerging Risks (ESENER), the fulfilment of legal duties is the strongest incentive for the prevention of psychosocial risks. Clients' complaints and concern about image are also important. The wish to decrease absenteeism and improve performance does not seem to be an incentive, and pressure by labour inspections only plays a marginal role (Velásquez, 2012).

The review delivered almost no data on workplace structural characteristics that may influence the prevention of psychosocial risks. Some publications described which industries were selected for the SLIC campaign - mainly health and social care, hotels and restaurants, transport and retail (Lerouge, 2012; SLIC, 2012; Stadler and Splittgerber, 2014), without suggesting causal relationships with outcomes. Mellor et al. (2011) indicated that the British Management Standards were first piloted in industries with high levels of stress-related absence - government, health services, education and finance. 


\subsubsection{Intervention measures and underlying mechanisms}

We defined five groups of publications depending on the kind of government intervention they addressed: workplace visits ( 9 publications), public policies (9), development of tools and instruments (4), overall inspection activities including a range of unspecified measures (3), and alternative strategies such as supply chain initiatives and other systemic strategies (1). Nine categories of generative mechanisms underlying these measures emerged out of the coding process. Most publications contained several mechanisms.

Dialogue between inspectors and employers, employees, staff representatives or social partners was most frequently mentioned (13 publications). For example, Bruhn and Frick (2011) stressed the central role of negotiations between inspectors and managers to reach a common perception of psychosocial risks, and Starheim and Bøgehus (2014) observed strategies employed by inspectors to disseminate information across the social spaces of the workplace in order to create a positive dynamic. Enlightenment (12 papers) is a frequent and similar strategy; it aims at educating, building capacity and promoting voluntary compliance through advice, guidance, tools and support by consultants.

More than one third of the publications (9) noted a focus on procedures rather than on content in OHS enforcement, with inspectors auditing systems and requiring risk assessments, and authorities that promote a risk management approach. Several authors are critical of this tendency (Frick, 2014; Jespersen et al., 2014; Johnstone et al., 2011; Lippel et al., 2011).

Deterrence ( 8 publications) is a strategy based on the threat of sanctions, pressure and a "command and control" inspection style. Hasle and Petersen (2004) and Walters et al. (2011) suggested that deterrence might have positive effects; the other publications rather highlighted its rarity. Some publications (6) indicated that time plays a role in the inspection of psychosocial risks. Inspectors use time strategies (Quinlan et al., 2009; Starheim and Bøgehus, 2014); providing companies with time to assimilate concepts and translate them into practice (Lippel and Quinlan, 2011), conducting repeated visits (Bruhn, 2006; Hansen et al., 2015; Quinlan et al., 2009), or focussing on long term improvements (Bruhn, 2009; Starheim and Bøgehus, 2014). Several authors cited flexibility (6 papers). For example, Bruhn (2006) indicated that inspectors must adapt their inspection style on a case-by-case basis, negotiate risk assessments, and be flexible about solutions. Johnstone et al. (2011) referred to the concept of responsive regulation, according to which inspectors tailor their responses to the ability of an employer to self-regulate.

Some publications (3) dealt with the question of focussing on specific psychosocial issues (risk factor approach) or promoting a holistic understanding (Rasmussen et al., 2011; Toukas et al., 2015). According to Quinlan (2007), inspectors and employers may have a tendency to concentrate on particular symptoms, rather than on their generative context. Legitimising was mentioned as yet another mechanism in 3 publications. Starheim (2014) showed how inspectors' intervention might legitimise internal actors or initiatives. Hasle and Petersen (2004) insisted on the necessity of massive activities to make social partner agreements socially visible and a part of a company's external legitimacy. Finally, Leka et al. (2015b) considered that the traditional "problem perspective" in OHS, focussing on legal requirements, economic cases and negative outcomes, has a de-legitimising effect among employers.

\subsubsection{Outcomes}

Authors provided some kind of outcome evaluation in 18 publications. Among them, 7 did not provide empirical evidence to support their appraisal. The other 11 based their evaluation on data gathered through case studies, surveys, observations during workplace visits, interviews, document analysis or focus groups. Table 3 cross-tabulates the types of intervention measures with the outcome categories, and accordingly lists the references.

3.2.3.1. Positive outcomes. Positive results were reported in 4 publications (but only 1 peer-reviewed article). First, Hansen et al. (2015) reported that the Danish Working Environment Authority (WEA) is good at identifying issues in companies and that inspection has a clear impact. They also showed that, in Norway, inspected enterprises are more able than others to document their health and safety activities and to assess psychosocial risk factors; no significant differences on more specific psychosocial parameters were found. In sum, these outcomes match step 3 on the

Table 3

Outcomes of public intervention measures (sum > 25).

\begin{tabular}{|c|c|}
\hline Intervention measures & References \\
\hline $\begin{array}{l}\text { Inspection visits (9) } \\
\text { Positive outcomes (2) } \\
\text { Possibly positive (1) } \\
\text { Mixed (2) } \\
\text { Poor (2) } \\
\text { Not assessed (2) }\end{array}$ & $\begin{array}{l}\text { SLIC (2012)*, Stadler and Splittgerber (2014) } \\
\text { Toukas et al. (2015) } \\
\text { Starheim (2014)*, Velásquez (2012) } \\
\text { Lerouge (2012), Lippel et al. (2011) } \\
\text { Starheim and Bøgehus (2014), Jespersen et al. (2014) }\end{array}$ \\
\hline $\begin{array}{l}\text { Policies: Policy-mix of regulatory } \\
\text { Possibly positive outcomes (1) } \\
\text { Mixed (2) } \\
\text { Poor (6) } \\
\text { Not assessed (1) }\end{array}$ & $\begin{array}{l}\text { proaches (6); Policies on regulated self-regulation, including psychosocial issues (2); Policies on social dialogue (1) } \\
\text { Hasle and Petersen (2004) } \\
\text { Frick (2014), Quinlan et al. (2009)* } \\
\text { Bruhn (2006), Hasle and Petersen (2004), Leka et al. (2015b), Lerouge (2014), Quinlan (2007)*, Walters et al. (2011) } \\
\text { Lippel and Quinlan (2011) }\end{array}$ \\
\hline $\begin{array}{l}\text { Development of methods, tools, } i \\
\quad \text { Management standards } \\
\text { Poor outcomes (1) } \\
\text { Not assessed ( } 3 \text { ) }\end{array}$ & $\begin{array}{l}\text { vedish inspection methods, Danish inspection tool, Norwegian guidelines on healthy organisational change and British } \\
\text { Mellor et al. (2011)* } \\
\text { Bruhn and Frick (2011), Rasmussen et al. (2011), Saksvik et al. (2007) }\end{array}$ \\
\hline $\begin{array}{l}\text { Inspection activities overall ( } 3 \text { ) } \\
\text { Positive outcomes (1) } \\
\text { Poor (1) } \\
\text { Not assessed (1) }\end{array}$ & $\begin{array}{l}\text { Hansen et al. }(2015)^{*} \\
\text { Johnstone et al. }(2011)^{*} \\
\text { Bruhn (2009) }\end{array}$ \\
\hline $\begin{array}{l}\text { Alternative methods (1) } \\
\text { Positive outcomes ( } 1 \text { ) }\end{array}$ & Walters et al. (2011) \\
\hline
\end{tabular}

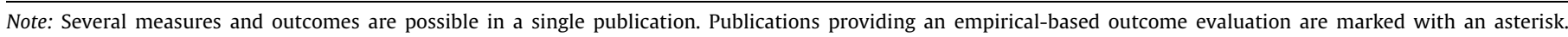
Number of publications specified between brackets. 
impact ladder described in Section 2.6 (improvements in the enterprises' work environment efforts).

Secondly, the SLIC (2012) reported on its 2012 European inspection campaign on psychosocial risks. On the whole, employers were cooperative and interested in receiving information and advice. The campaign was somewhat successful at inducing measures, contributing to OSH management and prevention in the enterprises, informing employers and workers, raising awareness of psychosocial risks and increasing adequate risk assessments. These outcomes correspond to steps 1 (changes in knowledge at the workplaces), 2 (changes in attitudes at the workplaces) and 3 of the impact ladder.

Thirdly, the implementation of the SLIC campaign in Germany was the subject of a peer-reviewed article by Stadler and Splittgerber (2014). They found a high acceptance of the campaign in most workplaces (step 2). Finally, the report by Walters et al. (2011) yielded two positive CMO configurations. One concerned a supply chain initiative by the Swedish WEA in large oil corporations. It resulted in preventive measures against robberies in the majority of franchised stations (step 4: improved production technology and safer work processes). These initiatives relied on a convergence of interests and efforts of social interest groups, regulators and media attention, creating threats to business, as well as on negotiation with the companies at the head of the supply chains. The other configuration involved promotional strategies in northern countries. They aimed at improving OHS management systems and at reaching "hard-to-reach" groups, through enlightenment and promotion of local dialogue between employers and workers. The authors reported on a positive - if not always ideal - evolution of norms. Inspection and surveillance of OHS management by the Swedish WEA is accepted, and enterprises generally comply with its requirements, including those on psychosocial risks (steps 2 and 3).

3.2.3.2. Possibly positive outcomes. In two cases, peer-reviewed articles suggested the possibility of positive results, without specifying them, nor providing empirical evidence. Hasle and Petersen (2004) studied agreements between social partners. They suggested that agreements consisting of efforts based on legal standards (such as a Danish agreement on monotonous and repetitive work) might have positive outcomes. Voluntary agreements on human resources policies could also have positive health and safety outcomes, but these are restricted to the most committed companies that are more likely to make use of them. Finally, Toukas et al. (2015) reported on the SLIC campaign; they distinguished a traditional inspection model focussing on singular problematic situations, and a modern, more holistic but also less frequent approach to inspection. The latter seems more effective.

3.2.3.3. Mixed outcomes. Mixed results were found in 4 papers ( 2 peer-reviewed). Frick (2014) studied the implementation of systematic work environment management in Sweden. Employers, safety representatives and authorities have positive opinions on inspection visits and on their results, especially for technical risks and in larger companies (impact step 5: reduction in exposures, including risks of accidents). However, more generally considered, implementation of systematic management is too often formal, and there is not much improvement in organisational and psychosocial issues. In Australia, Quinlan et al. (2009) observed a growing but reactive and fragmented response from regulators to changing work arrangements. Inspectors are successful at explaining law and enhancing compliance (step 1), but have difficulties in securing an enduring level of compliance. In Denmark, Starheim (2014) conducted case studies on workplace reaction to inspection visits. Some companies improve in accordance with the inspectors' requirements (steps 3 and 4). In other companies, improvement measures differ from the requirements. The result depends on the workplace's internal dynamics, on the agreement with the problem description made by the inspector, on the acceptance of suggested solutions and on the workplace's capacity to understand the causes of the problems. Lastly, Velásquez (2012) mentioned that the Nordic way of inspecting psychosocial risks seems more effective than the approach of other EU countries. However, this result may entail a confusion between the roles of inspectors and employers, because risk assessment and prevention are fundamentally employer duties. He also indicated that compliance is lower on psychosocial issues than on other OHS issues.

3.2.3.4. Poor outcomes. Finally, 10 publications (7 peer-reviewed) showed an absence of positive outcomes for public policies (6), inspection visits (2), overall inspection activities (1), and the development of inspection tools (1). Bruhn (2006) reported on the introduction of "regulated self-regulation" as the main strategy in the Swedish OSH policy, and on the inclusion of psychosocial factors in the concept of the work environment. Overall, the results remains rather formal. Hasle and Petersen (2004) mentioned that some agreements in Denmark tend to exclude inspector intervention on topics such as bullying, harassment and working hours. These agreements present increased implementation problems, particularly in passive or negatively disposed workplaces. Moreover, traditional collective agreements on wages, working hours, etc. rarely include work environment issues, and thus have no effect in this respect.

In Australia, Johnstone et al. (2011) observed an evolution of inspectorates' interventions, from a reactive approach to harassment issues to a broader approach covering more psychosocial risks. However, inspectors think that outcomes are poor in comparison with the time spent on investigations. Quinlan (2007) found that Australian regulatory responses to downsizing and restructuring do not have much influence on employers' practices. Most employers remain unaware of their legal duties. Risk assessment and worker consultation are cursory, planning for the effects of change is poor and employers tend to focus on the symptoms of stress, violence or bullying, rather than on their organisational roots.

At EU-level, Leka et al. (2015b) investigated the current policymix including regulatory approaches, agreements and voluntary systems. Results are disappointing. Few companies inform their workers on psychosocial risks and take appropriate action. Measures are often reactive; they focus on the individual, rehabilitation and return to work. In France, Lerouge $(2012,2014)$ predicted weak results for the SLIC inspection campaign; he suggested that due to a problem of law enforcement, the French approach might be less efficient than other national systems. In Québec, Lippel et al. (2011) studied psychosocial inspections based on the implementation of the general duty clause; according to union representatives, inspectorates' emphasis on procedural dimensions undermines the prevention agenda by individualising issues. In the UK, Mellor et al. (2011) assessed the implementation of the Management Standards on stress at work. They indicated that psychosocial scores from national surveys have remained constant since the introduction of the Standards. Most organisations implement a mix of preventive and reactive measures (most commonly: employee training and assistance programs), and not the preventive-organisational measures advocated by authorities. Finally, Walters et al. (2011) provided an overview of regulatory strategies in five industrialised countries. They found little evidence showing effectiveness of OHS management systems and promotional strategies aiming at improving these systems.

3.2.3.5. Outcomes by mechanisms and intervention measures. No obvious relationship emerged from the cross-tabulation of mecha- 

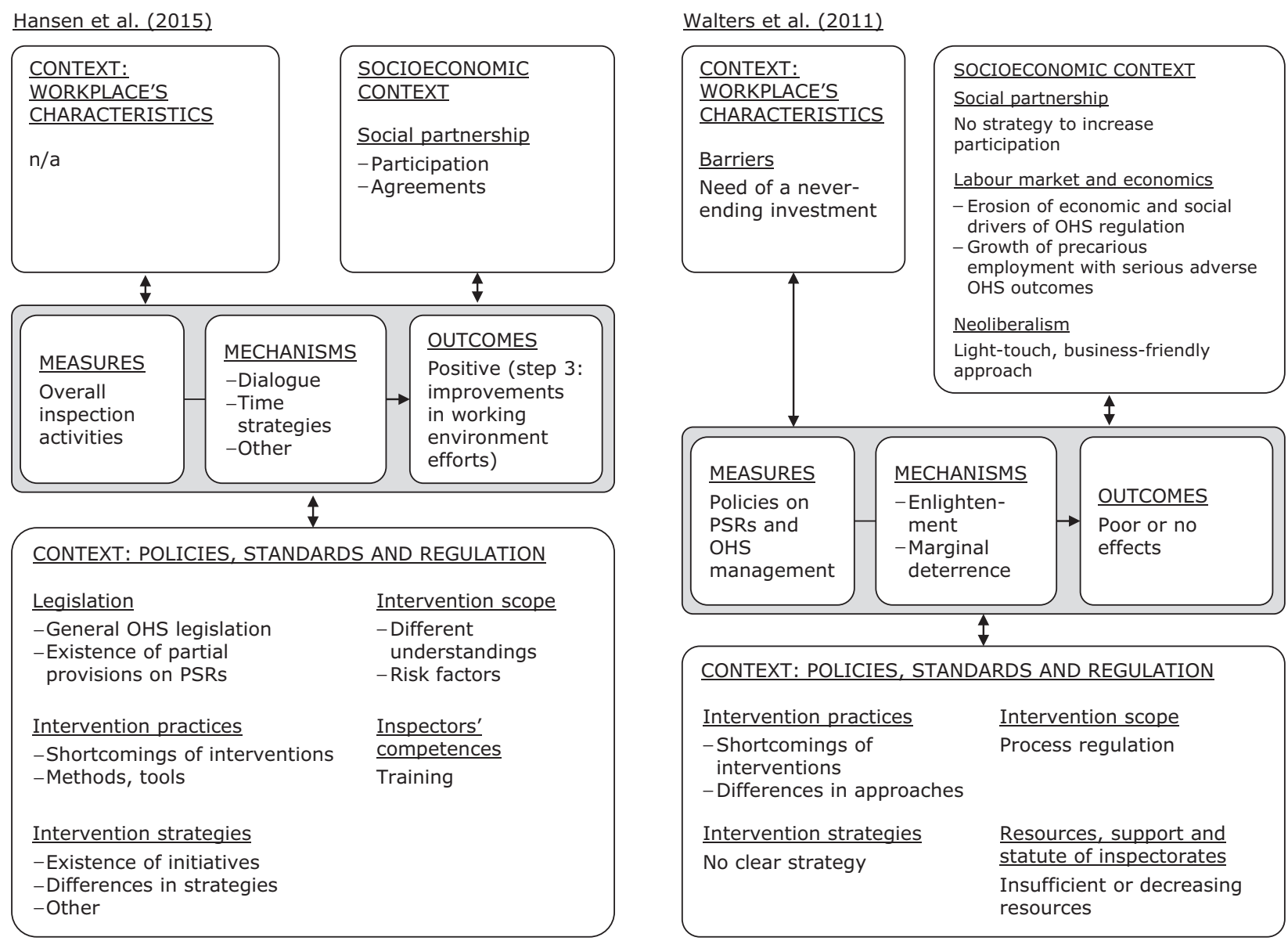

Fig. 4. Comparison of two CMO configurations extracted out of Hansen et al. (2015) and Walters et al. (2011). PSRs = psychosocial risks.

nisms and outcomes. By contrast, comparing the outcomes across the 5 categories of intervention measures, it appears that public policies on psychosocial risks mostly present poor results $(6 / 10)$, with no publication showing clear positive outcomes. Inspection visits and overall inspection activities display a more balanced account, with 3 publications suggesting negative outcomes, 2 mixed results, 1 possibly positive impacts and 3 positive outcomes. Finally, the publication about alternative strategies exhibited positive outcomes.

\subsubsection{Patterns of CMO configurations}

In order to assess which dimensions could enable or impede inspectors' action, and to ease the interpretation of the results despite their large heterogeneity, we chose to focus on two particularly exemplary CMO configurations, one with positive (Hansen et al., 2015) and the other negative (Walters et al., 2011) outcomes. Both were extracted out of international reviews on labour inspection. Fig. 4 schematically juxtaposes the two CMO configurations.

Hansen et al. (2015) reported on encouraging evaluation studies from Denmark and Norway. Inspection activities are based on dialogue, group interviews and a combination of repeated visits with other communication channels. There is a high degree of worker participation. Workplaces must have health and safety representatives and the social partners may conclude agreements on the work environment. According to the general duty provisions, employers must assess psychosocial risks, develop an action plan and call in experts if they lack knowledge. Specific provisions on the psychosocial work environment and on bullying complement the regulatory framework. On the other hand, there is no legal def- inition of the psychosocial work environment, nor specific regulation on some key risk factors (such as workload, time pressure or emotional demands). Psychosocial topics are priority areas in every country investigated. Intervention strategies are based on a riskfactor approach. Every country has practices on violence and threatening behaviour, bullying and sexual harassment, and lack of training. Risk factors related to the organisation of work or relational matters are often included in the inspection of other factors or in an overall assessment. Authorities may issue improvement notices on these issues. Some other dimensions, such as working hours and schedules, are not inspected in several countries. Inspection purposes and methods vary across countries, but in any case, industries with high risks, such as social and healthcare, education or public administration, are inspected as a priority. Most countries offer basic training, including psychosocial issues, for new inspectors, on-the-job training and continuing training activities. Specialised inspectors support their less experienced colleagues; they are sometimes organised in skills networks. Authorities develop tools and methods such as guidelines, checklists, structured interviews with employees and survey questionnaires. Despite all these initiatives, only 1-16\% of improvement notices specifically address the psychosocial work environment.

By contrast, Walters et al. (2011) provide a critical assessment of OHS policies in Australia, France, Canada (Québec), Sweden and the UK. Policy-mixes encompass inspection visits, promotion of OHS management systems (including psychosocial risks) and alternative methods for companies that are difficult to reach with conventional workplace visits. Enlightenment is a core principle and the threat of sanctions is marginal. Case studies demonstrate 
the importance of workplace inspections in systematic approaches to health and safety. However, there is little evidence for the effectiveness of the other policy instruments, such as promotional strategies and initiatives toward hard-to-reach companies. Besides, the mainstream "management system" approach of OHS has not been proven clearly effective. Actually, growing precariousness, increasingly contingent work arrangements and a neo-liberal climate have eroded the economic and social drivers of OHS regulation. In the five countries, there has been a regulatory shift toward "process regulation". However, authorities have not developed clear strategies and sufficient resources to achieve the goal, to increase worker participation and to deal with the consequences of the changing world of work. The new self-regulation approach has not led to sustained changes in inspection practices, even if inspectors are conscious of its value. There is an increased focus on procedural issues rather than on substance.

\subsubsection{Recommendations from the literature}

Most authors made recommendations for a better regulation of psychosocial risks. The largest category concerned inspection strategies (11 papers). Psychosocial risks should not be dealt with as normal technical regulations through traditional inspection methods (Bruhn and Frick, 2011; SLIC, 2012). Formal control of documents and procedures should not have first priority (Bruhn, 2006). The adoption of a "resource perspective" could be more convincing than the usual "problem perspective" (Leka et al., 2015b). Inspectorates should raise awareness, educate, challenge and advise companies and promote partnership beyond formal consultation (SLIC, 2012). Inspectors could contribute to change processes and influence the dynamics inside the workplace to reach long-term improvements, if they could invest enough time (Leka et al., 2015b; Saksvik et al., 2007; Starheim and Bøgehus, 2014). There is a need to get out of an individual and reactive approach mainly limited to bullying, and develop a collective and preventive approach (Lerouge, 2014). More qualitative measures of the outcomes should be developed to supplement the quantitative criteria (Frick, 2014). Finally, Walters et al. (2011) suggested examining the potential of supply chain initiatives and recalled the importance of face-to-face contact and fear of surveillance.

Actions at a legislative level were suggested in 6 publications. Several authors recommended examining how far it would be possible to specify legal requirements on psychosocial risks. Such provisions would enable enterprises to know their duties better, and inspectors to act more effectively (Bruhn and Frick, 2011; Hansen et al., 2015; Lippel et al., 2011; Toukas et al., 2015). Johnstone et al. (2011) and Quinlan (2007) contend that an explicit reference to psychosocial risks, restructuring and contingent work should be incorporated into general duty provisions; codes on downsizing/ restructuring and workload should be developed.

An evolution of the inspectors' role and competences was deemed necessary in 5 papers. Inspectors need autonomy to adjust to individual situations. Further developments of inspectors as a professional group are required, which necessitates a strong internal dialogue. More training in assessing and preventing psychosocial risks, and in conducting interviews, would help inspectors (Bruhn, 2006; Bruhn and Frick, 2011; Jespersen et al., 2014; Rasmussen et al., 2011; Toukas et al., 2015). Likewise, 3 publications recommended further developing inspection tools, methods, guidance and protocols (Mellor et al., 2011; Quinlan, 2007; Rasmussen et al., 2011). Finally, some publications suggested actions in the field of industrial relations and labour market. Johnstone et al. (2011) state that psychosocial risks should be recognised in industrial relations issues. Hasle and Petersen (2004) hold the view that agreements between social partners must not exclude the authorities: a cooperation between the partners and the state is necessary to put pressure on reticent firms and to control companies that are not organised at a branchlevel. Lastly, Frick (2014) called for a slowed-down deregulation of the labour market and for the prevention of social dumping, in order to counter the growing gap between the best and the worst employers.

\section{Discussion}

\subsection{Refined programme theory}

Realist reviews start and end with theory. We began with a rough programme theory and refined it in the course of the review. A core feature of the refined programme theory (Fig. 3, Section 3.2) is the importance of national contexts, addressed in all papers but one. This is coherent with Cheng's (2015) conclusion on the necessity of a comprehensive understanding of the local context to develop effective actions against work-related stress. The comparison of the $30 \mathrm{CMO}$ configurations revealed the difficulty in extrapolating the results from studies to different settings. Because of this large variety, we chose to apply the refined programme theory to two synthetic reports (Hansen et al., 2015; Walters et al., 2011) to provide a pattern of CMO configurations. It allowed us to highlight the characteristics of the Nordic way of inspecting the psychosocial work environment, to explain its rather positive outcomes, and to compare them to the more disappointing results observed in other advanced market economies. The still highly organised labour market in Nordic countries has a determining influence on inspectors' interventions. Hasle and Petersen (2004) note the difficulty of using agreements between social partners as a public policy instrument in lower structured labour markets. Nevertheless, the Nordic countries should not be schematically contrasted with other political regimes. Frick (2014) indeed draws nuanced conclusions on the implementation of the systematic work environment management in Sweden. Hasle and Petersen (2004) also suggest that agreements could entail some risks for authorities, especially the risk of excluding inspectors' interventions. Beyond the Nordic model, support by social partners and participation within companies are important success conditions for government interventions. However, several authors note that evolutions of the global economy undermine an efficient collaboration with the social partners. Changed work arrangements may have negative consequences on workers' health, with an increase in psychosocial risks and more obstacles to the management of occupational health and safety (Quinlan, 2007; Quinlan et al., 2009; Toukas et al., 2015; Walters et al., 2011).

Tompa et al. (2007) suggests that labour inspectors have to be in the field for regulation to be effective. Yet, many publications report on the limited resources of inspectorates to make direct and repeated contact with companies. According to Weil (2008), resource limitations are the major problem facing labour inspectorates worldwide. Investigation of psychosocial and organisational risks require more time than the traditional safety hazards. Workplaces have become more difficult to reach; this has further increased the time pressure on inspectors. In the wake of New Public Management, management indicators and incentive systems are meant to measure and improve the performance of labour inspectorates (Frick, 2014; Quinlan, 2007). This trend may incite agencies and inspectors to increase the numbers of visits, reduce their duration and lead to a focus on easy-to-assess topics (Frick, 2014).

We initially hoped to find information on workplace characteristics that might facilitate inspectors' interventions, such as the industry or demographic structure. However, very few publications provide such data and authors more often highlight the impediments. Only company size is regularly cited as an important factor; large companies are more able to manage these issues. 
Prevention practices within companies are also a marginal topic in the publications.

Regarding the intervention measures, we found several detailed accounts on the inspection of the psychosocial work environment in Nordic countries, continental Europe, the UK, Australia and Canada (Québec). In most countries, inspectors indirectly address psychosocial risks through the assessment of the OHS management systems inside workplaces. They check if companies have processes to ensure the detection and prevention of the whole range of occupational hazards, including psychosocial issues. Over recent decades, this approach has been the main strategy to encourage employers to fulfil their general prevention duties (Walters et al., 2011). In some Nordic countries, inspectors conduct specific psychosocial inspections. However, routine inspections of the psychosocial work environment are an exception outside Denmark (Rasmussen et al., 2011).

The publications highlight several kinds of government interventions: workplace visits, development of instruments, promotion of social dialogue, regulatory and voluntary approaches on systematic OHS management, etc. A majority of references do not strictly focus on inspection visits: inspectors' activities are included in a wide array of interrelated measures. This is important to keep in mind when trying to assess the efficiency of inspection visits. It seems difficult to isolate their outcomes, independently of other public policy measures.

According to the realist logic, interventions do not directly cause outcomes. They are mediated by mechanisms, which are a function of the context (Wong et al., 2013b). Enlightenment, advice and dialogue are by far the most frequent strategies used by inspectorates to address psychosocial risks and foster compliance. No author mentioned deterrence as a common approach. This is not surprising. Psychosocial risks are complex and relatively new for labour inspectors. In many countries, specific legal provisions on this topic do not exist; moreover, the boundary between prevention of psychosocial risks and managerial prerogatives is fuzzy. Nevertheless, some authors consider deterrence as a necessary ingredient for an efficient intervention by labour inspectors. Inspection styles seem to some degree culturally and socially conditioned: Bruhn (2009) stresses the differences between male "technicians" with a command-and-control inspection style, and newly hired "academics" addressing soft factors and preferring deep investigations. Bruhn (2006) also notes that an inspector deploys several styles depending on the workplace's reactions. Indeed, most publications report on an array of interconnected mechanisms, rather than on isolated ones. This is probably a reason why this review did not find any regular relationship between mechanisms and outcomes. Depending on the study, the same mechanisms lead to positive or negative results, and positive impacts are associated with various mechanisms.

A striking feature is the very small quantitative evidence on the effectiveness of psychosocial inspections. Few publications reported on quantitative results and even fewer were primary research articles. Furthermore, only 5 publications specifically aimed at evaluating the outcomes of interventions. In comparison, the Cochrane review on enforcement tools for preventing occupational diseases and injuries (Mischke et al., 2013) identified 23 studies, of which 16 were quantitative; several were randomised controlled trials, controlled intervention studies or interrupted time-series. As mentioned by Starheim and Bøgehus (2014), research on the inspection of psychosocial issues has only just begun. The available data delivers a rather mixed picture. Peerreviewed articles are overrepresented in publications reporting no positive outcomes, mixed results or possibly positive results. Publications reporting positive results mostly belong to the grey literature. Several papers on workplace visits showed a positive impact; but, by contrast, most publications on public policies were characterised by the absence of positive outcomes. This result confirms the existence of a gap between policy and practice (Langenhan et al., 2013; Leka et al., 2011b; Zoni and Lucchini, 2012). Inspectors may be rather successful at a micro-level, convincing employers during their inspection duties, while policies at a macro-level do not seem to fulfil expectations. A possible explanation would be that inspectors are only able to inspect a fraction of workplaces, and maybe not the worst ones.

Evaluating the outcomes of state interventions on psychosocial risks is a challenge. Safety improvements can be measured through standard indicators such as injury rates. Equivalent easy-to-access information does not exist for the psychosocial work environment; specific assessment tools are needed to gather data. Moreover, the outcomes of an intervention can be multiple: better informed stakeholders, changes in attitudes, stronger prevention efforts, safer work processes, reduced exposures, lower rates of workrelated diseases, improved health, etc. An impact ladder such as suggested by Hansen et al. (2015) helps specify the criteria and enables a comparison between studies. Finally, several publications insist on the importance of long time-spans and repeated visits for effective inspection. Outcomes may be difficult to assess within the tight schedules of applied research and public policy evaluation.

\subsection{Strengths and limitations of the review}

Strengths of this review include the use of a realist approach to relate outcomes to their contexts and generative mechanisms. This approach is consistent with the nature of the existing publications, which describe contexts in detail, provide information on mechanisms, but rarely assess results. Another interest is the development of an enriched programme theory encompassing a wide array of influences on inspector intervention.

The main limitation to the generalisability of our findings is the lack of evaluation studies. A few quantitative studies from Nordic countries show positive results. It is not clear to what extent they can be extrapolated to other national contexts. Lindblom and Hansson (2004) warn about the difficulty of international comparisons: many factors interact in complex ways with agency activities and resources. According to the SLIC report (2012), not every method is suitable in a given country. The Nordic corporatist tradition and highly structured labour market probably facilitate the use of collective interviews and questionnaire inquiries. These tools might be less functional in more liberal regimes. Anyway, without evaluation studies outside Northern Europe, comparisons are currently not possible. In addition, it would be useful for regulatory agencies to know in which industries and types of workplaces they could have the largest impact. To answer these questions, there is a need for quantitative and mixed-method research, in order to assess outcomes, and link them with their contexts and mechanisms. The SECO is currently conducting a longitudinal evaluation study for this purpose.

Our resources allowed us to involve only one researcher in the literature search, data extraction and information coding. This is another limitation of our review. According to Mouter and Vonk Noordegraaf (2012), performing an intercoder reliability check in qualitative research is very time consuming. It is also more difficult when the reviewed literature does not discuss exactly the same topic as the one under study. In our case, the included publications turned out to be very heterogeneous; indeed, the coding scheme included more than 70 hierarchically ordered categories. Moreover, Marchal et al. (2012) stress that theory-driven evaluation can be resource- and time-intensive, because it assesses not only efficacy, but also the underlying theory. This might be a reason why intercoder reliability is not mentioned in the publication standards for realist syntheses (Wong et al., 2013a). 
To compensate for a possible subjectivity bias, we strived for a transparent extraction and coding process, so that the data might be reanalysed. Both authors contributed to the definition of the search process, the selection of databases and the choice of inclusion and exclusion criteria. Data extraction and coding proved consistent and reliable based on the check by the second author. Our results were also validated by key stakeholders during a meeting with a panel of about 20 OHS specialists within the SECO (federal labour inspectors, lawyers, work psychologists, ergonomists and other experts). At last, the whole review process was regularly discussed and improved in collaboration with other researchers within the SECO.

Certain questions remain unresolved. First, there is a debate on the relevance of specific provisions for the prevention of psychosocial risks. Some authors consider it unnecessary to legislate on these issues, because they are covered by employers' general duties (Lerouge, 2014; Velásquez, 2012). However, more authors defend the view that specific references, at least in the general duty provisions, would facilitate the work of labour inspectors and the implementation of preventive measures (Bruhn and Frick, 2011; Hansen et al., 2015; Johnstone et al., 2011; Lippel and Quinlan, 2011; Lippel et al., 2011; Quinlan, 2007; Toukas et al., 2015). A second open question concerns the limits of inspectors' intervention: how much should they contribute to the assessment of the psychosocial risks? In some Nordic countries, inspectors conduct specific psychosocial risk assessments. However, in most countries, they rather evaluate the capacity of employers to assess and manage risks on their own. Starheim and Bøgehus (2014) suggested that inspectors should even contribute to the organisational prevention process: who should support the workplaces to solve their problems, if inspectors were to concentrate only on the assessment part? Considering inspectorates' limited resources, we would rather suggest a cooperation between authorities, social partners and occupational health consultants or services. For example, employer associations could support their members - especially small and medium enterprises - by offering them the possibility to call in experts recommended or employed by the association.

\section{Conclusions}

To our knowledge, this systematic review is the first to deal with the inspection of the psychosocial work environment. We chose a realist approach to address this topic. The literature search identified publications from Europe, Australia and Canada. Authors primarily describe national or international settings that shape inspector interventions; some papers report on quantitative results. Overall, the picture is mixed. Inspectors prove quite successful at convincing employers during visits, while prevention policies at a more macro-level seem to fall short of their objectives.

We propose a theoretical model of the influences on labour inspector effectiveness in this field. It could be used for evaluation studies in order to explain and more easily compare their results. However, this implies that quantitative or mixed-method studies are conducted in the future. Such studies certainly present challenges. The loose definition of psychosocial risks is a substantial issue; different studies address this topic through different theoretical lenses and definitions. Some evaluate the impact of inspection on specific risk factors, while others address the psychosocial work environment as a whole. Moreover, long-term inspection effects should certainly be assessed. Finally, the prospect of an evaluation may worry labour inspectors, especially with such a relatively touchy issue.

Nevertheless, Lindblom and Hansson (2004) contend that labour inspectors have good opportunities to systematically assess the effectiveness of their action and to compare different intervention methods. To this end, they recommend developing stringent evaluation processes, which would isolate the effect of inspection from other factors; evaluation could be integrated in the general planning of inspection activities. We think that realist evaluation is an adequate approach to tackle these challenges. Indeed, it does not aim at determining whether inspection has an effect on the psychosocial work environment - which may be disappointing but where, in which situations, and how. Identifying such success factors would allow inspectorates to make informed decisions about the focus of their actions.

\section{Acknowledgements}

We gratefully thank Dr. Margaret Graf, Dr. Marc Arial, Mrs. Stephanie Lauterburg, Mr. Pascal Richoz, Ms. Margot Vanis and our other colleagues at the SECO for their support. We also express our gratitude toward the two anonymous reviewers for their precious comments.

\section{Appendix A. Supplementary material}

Supplementary data associated with this article can be found, in the online version, at http://dx.doi.org/10.1016/j.ssci.2017.02.012.

\section{References}

Baril-Gingras, G., Bellemare, M., Brun, J.-P., 2006. The contribution of qualitative analyses of occupational health and safety interventions: an example through a study of external advisory interventions. Saf. Sci. 44, 851-874. http://dx.doi.org/ 10.1016/j.ssci.2006.05.003.

Berthelette, D., Bilodeau, H., Leduc, N., 2008. Pour améliorer la recherche évaluative en santé au travail. Sante publique 20,171-179.

Bouffartigue, P., 2012. Mesurer les "Risques psychosociaux"?, Mesures et démesures du travail - XIIIèmes Journées Internationales de Sociologie du Travail, 25-27 janvier 2012, Bruxelles, Belgium. <https://halshs.archivesouvertes.fr/halshs-00767900/document> (Nov. 1, 2016).

Bruhn, A., 2006. The inspector's dilemma under regulated self-regulation. Policy Pract. Health Saf. 4, 3-23. http://dx.doi.org/10.1080/14774003.2006.11667679.

Bruhn, A., 2009. Occupational unity or diversity in a changing work context? The case of Swedish labour inspectors. Policy Pract. Health Saf. 7, 31-50. http://dx. doi.org/10.1080/14774003.2009.11667733.

Bruhn, A., Frick, K., 2011. Why it was so difficult to develop new methods to inspect work organization and psychosocial risks in Sweden. Saf. Sci. 49, 575-581. http://dx.doi.org/10.1016/j.ssci.2010.07.011.

Cheng, Y.W., 2015. Policy responses to work-related stress: examining Taiwan's experiences from a welfare state regime perspective. Saf. Sci. 78, 111-116. http://dx.doi.org/10.1016/j.ssci.2015.04.018.

Creswell, J.W., 2014. Research Design: Qualitative, Quantitative, and Mixed Methods Approaches. SAGE, Los Angeles.

Dalkin, S.M., Greenhalgh, J., Jones, D., Cunningham, B., Lhussier, M., 2015. What's in a mechanism? Development of a key concept in realist evaluation. Implementation Sci. 10, 1-7. http://dx.doi.org/10.1186/s13012-015-0237-x.

Davezies, P., 2001. Le stress au travail: entre savoirs scientifiques et débat social. Perform, Stratégies et Facteur Hum 1, 4-7.

de Gaulejac, V., 2010. RPS: Quels diagnostics? Enjeux scientifiques et politiques. Nouv. Rev. Psychosociol. 10, 51-70. http://dx.doi.org/10.3917/nrp.010.0051.

Ertel, M., Stilijanow, U., Iavicoli, S., Natali, E., Jain, A., Leka, S., 2010. European social dialogue on psychosocial risks at work: benefits and challenges. Eur. J. Ind. Relat. 16, 169-183. http://dx.doi.org/10.1177/0959680110364830.

Frick, K., 2014. The 50/50 implementation of Sweden's mandatory systematic work environment management. Policy Pract. Health Saf. 12, 23-46. http://dx.doi. org/10.1080/14774003.2014.11667802.

Gagliardi, D., Marinaccio, A., Valenti, A., Iavicoli, S., 2012. Occupational safety and health in Europe: lessons from the past, challenges and opportunities for the future. Ind. Health 50, 7-11. http://dx.doi.org/10.2486/indhealth.MS1342.

Gillespie, B.M., Marshall, A., 2015. Implementation of safety checklists in surgery: a realist synthesis of evidence. Implementation Sci. 10, 1-14. http://dx.doi.org/ 10.1186/s13012-015-0319-9.

Hansen, T., Lidsmoes, L.C., Laursen, P., Mathiassen, L., Jensen, A.-M., Suhr Raby, C., Sorensen, L., Jurvelius, H., Rintala, J., Hardarson, S., Sveinsdóttir, P., Rosenberg Sovik, S., Hjorth, B., Schyberg, P., Tiborn, M., 2015. Psychosocial Working Environment: Workplace Inspection of the Psychosocial Working Environment in the Nordic Countries. Nordic Council of Ministers, Copenhagen. <http:// norden.diva-portal.org/smash/get/diva2:795004/FULLTEXT01.pdf>.

Hasle, P., Petersen, J., 2004. The role of agreements between labour unions and employers in the regulation of the work environment. Policy Pract. Health Saf. 2, 5-23. http://dx.doi.org/10.1080/14774003.2004.11667641. 
Higgins, A., O'Halloran, P., Porter, S., 2012. Management of long term sickness absence: a systematic realist review. J. Occup. Rehabil. 22, 322-332. http://dx. doi.org/10.1007/s10926-012-9362-4.

Jain, A.K., 2011. Development and Implementation of Policies for the Management of Psychosocial Risks: Exploring the Role of Stakeholders and the Translation of Policy into Practice in Europe. University of Nottingham. <http://eprints. nottingham.ac.uk/12295/2/Aditya_Jain_Thesis.pdf> (Nov. 1, 2016).

Jespersen, A.H., Hasle, P., Hohnen, P., Madsen, C.U., 2014. Audit of psychosocial risk management systems: between tacit knowledge and standardization, In: Broberg, O., Hasle, N.F.P., Jensen, P.L., Kabel, A., Larsen, M.E., Weller, T. (Eds.), 11th International Symposium on Human Factors in Organisational Design and Management (ODAM 2014) and 46th Annual Nordic Ergonomics Society Copenhagen (Denmark), pp. 845-850. <http://proceedings.dtu.dk/fedora/ repository/dtu:2506> (Nov. 1, 2016)

Johnstone, R., Quinlan, M., McNamara, M., 2011. OHS inspectors and psychosocial risk factors: evidence from Australia. Saf. Sci. 49, 547-557. http://dx.doi.org/ 10.1016/j.ssci.2010.09.016.

Kortum, E., Leka, S., 2014. Tackling psychosocial risks and work-related stress in developing countries: the need for a multilevel intervention framework. Int. J. Stress Manage. 21, 7-26. http://dx.doi.org/10.1037/a0035033.

Kortum, E., Leka, S., Cox, T., 2010. Psychosocial risks and work-related stress in developing countries: health impact, priorities, barriers and solutions. Int. J. Occup. Med. Environ. Health 23, 225-238. http://dx.doi.org/10.2478/v10001010-0024-5.

Langenhan, M.K., Leka, S., Jain, A., 2013. Psychosocial risks: is risk management strategic enough in business and policy making? Saf. Health Work 4, 87-94. http://dx.doi.org/10.1016/j.shaw.2013.04.003.

Leka, S., Cox, T., 2008. PRIMA-EF: Guidance on the European Framework for Psychosocial Risk Management: A Resource for Employer and Worker Representatives. <http://www.prima-ef.org/> (06.03.2016).

Leka, S., Jain, A., Cox, T., Kortum, E., 2011a. The development of the European framework for psychosocial risk management: PRIMA-EF. J. Occup. Health 53, 137-143. http://dx.doi.org/10.1539/joh.010010.

Leka, S., Jain, A., Iavicoli, S., Di Tecco, C., 2015a. An evaluation of the policy context on psychosocial risks and mental health in the workplace in the European Union: achievements, challenges, and the future. BioMed Res. Int. 2015, 18. http://dx.doi.org/10.1155/2015/213089.

Leka, S., Jain, A., Iavicoli, S., Vartia, M., Ertel, M., 2011b. The role of policy for the management of psychosocial risks at the workplace in the European Union. Saf. Sci. 49, 558-564. http://dx.doi.org/10.1016/j.ssci.2010.02.002.

Leka, S., Van Wassenhove, W., Jain, A., 2015b. Is psychosocial risk prevention possible? Deconstructing common presumptions. Saf. Sci. 71, 61-67. http://dx. doi.org/10.1016/j.ssci.2014.03.014.

Lerouge, L., 2012. French labour inspectors and psychosocial risk: What are the possible actions, In: Rufino San José, M.M.N., Cristóbal, González Vicente, Emilio (Eds.), Prevention on Psychosocial Risks and Quality of Life at Work International Yearbook 2012. Labour Inspection and Psychosocial Risk Assessment: Progress and Resistance from a European Perspective. Labour Health Secretary UGT_CEC, Madrid, pp. 43-59. <http://portal.ugt.org/ saludlaboral/observatorio/publicaciones/anuarios/Anuario2012.pdf> (Nov. 1, 2016)

Lerouge, L., 2014. Contribution à l'étude juridique des risques psychosociaux au travail. Aspects de droit national, de droit comparé, d'interdisciplinarité, COMPTRASEC UMR 5114. Université de Bordeaux. <https://halshs.archivesouvertes.fr/tel-01082773> (Nov. 1, 2016).

Lhuilier, D., 2010. Les "risques psychosociaux»: entre rémanence et méconnaissance. Nouv. Rev. Psychosociol. 11-28. http://dx.doi.org/10.3917/ nrp.010.0011.

Lindblom, L., Hansson, S.O., 2004. Evaluating workplace inspections. Policy Pract. Health Saf. 2, 77-91. http://dx.doi.org/10.1080/14774003.2004.11667651.

Lippel, K., Quinlan, M., 2011. Regulation of psychosocial risk factors at work: an international overview. Saf. Sci. 49, 543-546. http://dx.doi.org/10.1016/j. ssci.2010.09.015.

Lippel, K., Vézina, M., Cox, R., 2011. Protection of workers' mental health in Québec: do general duty clauses allow labour inspectors to do their job? Saf. Sci. 49, 582-590. http://dx.doi.org/10.1016/j.ssci.2010.04.011.

Loriol, M., 2010. La construction sociale du stress: entre objectivation, subjectivité et régulations collectives des difficultés au travail. Nouv. Rev. Psychosociol. 111-124. http://dx.doi.org/10.3917/nrp.010.0111.

MacEachen, E., Kosny, A., Stahl, C., O'Hagan, F., Redgrift, L., Sanford, S., Carrasco, C., Tompa, E., Mahood, Q., 2016. Systematic review of qualitative literature on occupational health and safety legislation and regulatory enforcement planning and implementation. Scand. J. Work Environ. Health 42, 3-16. http://dx.doi.org/ 10.5271 /sjweh.3529.

Marchal, B., van Belle, S., van Olmen, J., Hoerée, T., Kegels, G., 2012. Is realist evaluation keeping its promise? A review of published empirical studies in the field of health systems research. Evaluation 18, 192-212. http://dx.doi.org/ 10.1177/1356389012442444.

Mellor, N., Mackay, C., Packham, C., Jones, R., Palferman, D., Webster, S., Kelly, P., 2011. 'Management standards' and work-related stress in Great Britain: progress on their implementation. Saf. Sci. 49, 1040-1046. http://dx.doi.org/ 10.1016/j.ssci.2011.01.010

Mischke, C., Verbeek, J.H., Job, J., Morata, T.C., Alvesalo-Kuusi, A., Neuvonen, K., Clarke, S., Pedlow, R.I., 2013. Occupational safety and health enforcement tools for preventing occupational diseases and injuries. Cochrane Database Syst. Rev. 8. http://dx.doi.org/10.1002/14651858.CD010183.pub2.
Mouter, N., Vonk Noordegraaf, D.M., 2012. Intercoder reliability for qualitative research: You win some, but do you lose some as well?. In: Proceedings of the 12th TRAIL Congress, 30-31 Oktober 2012. TRAIL Research School, Rotterdam, Nederland. <http://repository.tudelft.nl/islandora/object/uuid:905f391d-4b2540cf-9292-e253b7e55db2?collection=research>.

Pawson, R., 2002. Evidence-based policy: the promise of 'realist synthesis'. Evaluation 8, 340-358. http://dx.doi.org/10.1177/135638902401462448.

Pedersen, L.M., Nielsen, K.J., Kines, P., 2012. Realistic evaluation as a new way to design and evaluate occupational safety interventions. Saf. Sci. 50, 48-54. http://dx.doi.org/10.1016/j.ssci.2011.06.010.

Quinlan, M., 2007. Organisational restructuring/downsizing, OHS regulation and worker health and wellbeing. Int. J. Law Psychiat. 30, 385-399. http://dx.doi. org/10.1016/j.ijlp.2007.06.010.

Quinlan, M., Johnstone, R., McNamara, M., 2009. Australian health and safety inspectors' perceptions and actions in relation to changed work arrangements. J. Ind. Relat. 51, 557-573. http://dx.doi.org/10.1177/0022185609339519.

Rasmussen, M.B., Hansen, T., Nielsen, K.T., 2011. New tools and strategies for the inspection of the psychosocial working environment: the experience of the Danish Working Environment Authority. Saf. Sci. 49, 565-574. http://dx.doi. org/10.1016/j.ssci.2010.06.002.

Robson, L.S., Clarke, J.A., Cullen, K., Bielecky, A., Severin, C., Bigelow, P.L., Irvin, E., Culyer, A., Mahood, Q., 2007. The effectiveness of occupational health and safety management system interventions: a systematic review. Saf. Sci. 45, 329-353. http://dx.doi.org/10.1016/j.ssci.2006.07.003.

Rycroft-Malone, J., McCormack, B., Hutchinson, A., DeCorby, K., Bucknall, T., Kent, B., Schultz, A., Snelgrove-Clarke, E., Stetler, C., Titler, M., Wallin, L., Wilson, V., 2012. Realist synthesis: illustrating the method for implementation research. Implementation Sci. 7, 33. http://dx.doi.org/10.1186/1748-5908-7-33.

Saksvik, P.Ø., Tvedt, S.D., NytrØ, K., Andersen, G.R., Andersen, T.K., Buvik, M.P. Torvatn, H., 2007. Developing criteria for healthy organizational change. Work Stress 21, 243-263. http://dx.doi.org/10.1080/02678370701685707.

SLIC, 2012. Psychosocial Risk Assessments: SLIC Inspection Campaign 2012 - Final Report. The Committee of Senior Labour Inspectors.

Stadler, P., Splittgerber, B., 2014. Psychosocial risks at work - an inspection campaign of the German labour authorities. ASU International. http://dx.doi org/10.17147/ASUI.2014-07-04-01.

Starheim, L., 2014. Displacements in organisations' responses to the inspections of their psychosocial working environment. In: Broberg, O., Hasle, N.F.P., Jensen, P. L., Kabel, A., Larsen, M.E., Weller, T. (Eds.), 11th International Symposium on Human Factors in Organisational Design and Management and 46th Annua Nordic Ergonomics Society Copenhagen, pp. 573-579. <http://proceedings.dtu. dk/fedora/repository/dtu:2391> (11.04.2015).

Starheim, L., Bøgehus, M., 2014. Labour inspection strategies addressing the psychosocial work environment. Policy Pract. Health Saf. 12, 53-70. http://dx. doi.org/10.1080/14774003.2014.11667797.

Tashakkori, A., Teddlie, C., 1998. Mixed Methodology: Combining Qualitative and Quantitative Approaches. SAGE, London.

Tompa, E., Trevithick, S., McLeod, C., 2007. Systematic review of the prevention incentives of insurance and regulatory mechanisms for occupational health and safety. Scand. J. Work Environ. Health 33, 85-95. http://dx.doi.org/10.5271/sjweh.1111.

Toukas, D., Delichas, M., Toufekoula, C., Spyrouli, A., 2015. The role of labour inspectorates in tackling the psychosocial risks at work in Europe: problems and perspectives. Saf. Health Work. http://dx.doi.org/10.1016/j.shaw.2015.06.001.

Velásquez, M., 2012. Comparative study of the psychosocial risks prevention management by the European inspection: United Kingdom, Autriche, Italy, France and Spain, In: Rufino San José, M.M.N., Cristóbal, González Vicente, Emilio (Eds.), Prevention on Psychosocial Risks and Quality of Life at Work - International Yearbook 2012. Labour Inspection and Psychosocial Risk Assessment: Progress and Resistance from a European Perspective. Labour Health Secretary UGT_CEC Madrid, pp. 19-41. <http://portal.ugt.org/saludlaboral/observatorio publicaciones/anuarios/Anuario2012.pdf> (Nov. 1, 2016).

Verbeek, J., Ruotsalainen, J., 2012. Letter to the editor re Pedersen et al. Saf. Sci. 50 1152. http://dx.doi.org/10.1016/j.ssci.2011.11.022.

Victor, L., 2008a. Systematic reviewing. Soc. Res. Update 54, 1-4.

Victor, L., 2008b. Systematic reviewing in the social sciences: outcomes and explanation. Enquire 1, 32-46.

Walters, D., Johnstone, R., Frick, K., Quinlan, M., Baril-Gingras, G., Thébaud-Mony, A. 2011. Regulating Workplace Risks: A Comparative Study of Inspection Regimes in Times of Change. Edward Elgar Publishing, Cheltenham, UK.

Weil, D., 2008. A strategic approach to labour inspection. Int. Labour Rev. 147, 349375. http://dx.doi.org/10.1111/j.1564-913X.2008.00040.x.

Wong, G., Greenhalgh, T., Westhorp, G., Buckingham, J., Pawson, R., 2013a. RAMESES publication standards: realist syntheses. BMC Med. 11, 21. http://dx.doi.org/ 10.1186/1741-7015-11-21.

Wong, G., Pawson, R., Owen, L., 2011. Policy guidance on threats to legislative interventions in public health: a realist synthesis. BMC Public Health 11, 222 http://dx.doi.org/10.1186/1471-2458-11-222.

Wong, G., Westhorp, G., Pawson, R., Greenhalgh, T., 2013b. Realist Synthesis: RAMESES Training Materials. <http://www.ramesesproject.org/index.php?pr= Project_outputs> (04.04.2015).

Yassi, A., Lockhart, K., Sykes, M., Buck, B., Stime, B., Spiegel, J.M., 2013. Effectiveness of joint health and safety committees: a realist review. Am. J. Ind. Med. 56, 424438. http://dx.doi.org/10.1002/ajim.22143.

Zoni, S., Lucchini, R.G., 2012. European approaches to work-related stress: a critical review on risk evaluation. Saf. Health Work 3, 43-49. http://dx.doi.org/10.5491 SHAW.2012.3.1.43. 